\title{
O Navegar Impreciso - A Privacidade no Facebook Vivenciada por seus Usuários
}

\author{
Manoel Pereira Junior ${ }^{1}$, Maria Lúcia Bento Villela ${ }^{1}$, Eliane Cristina de Freitas \\ Rocha $^{2}$, Raquel Oliveira Prates ${ }^{1}$ \\ ${ }^{1}$ Dept. de Ciência da Computação - Universidade Federal de Minas Gerais (UFMG) \\ Av. Antônio Carlos 6627 - Prédio do ICEx - Belo Horizonte - MG - Brasil \\ ${ }^{2}$ Escola de Ciência da Informação - Universidade Federal de Minas Gerais (UFMG) \\ Av. Antônio Carlos 6627 - Belo Horizonte - MG - Brasil \\ \{manoel, mvillela, rprates\}@dcc.ufmg.br, elianecfr@eci.ufmg.br
}

\begin{abstract}
This paper is an exploratory study of how privacy is handled by Facebook users. To achieve this goal a few methods were used, providing different perspectives on the issue - an online survey, the Semiotic Inspection Method (SIM) and the Communicability Evaluation Method combined with interviews about privacy issues. The conclusion is that users say they are worried about Facebook privacy regarding the disclosure of their personal information, especially photos; however, there were also major disruptions of communication related to the privacy of photographs.
\end{abstract}

Resumo. Este artigo investiga de maneira exploratória como a privacidade é tratada pelos usuários do Facebook. A fim de alcançar este objetivo, foram empregados métodos distintos, propiciando enfoques diferentes sobre a questão - um questionário online, o Método de Inspeção Semiótica (MIS) e o Método de Avaliação de Comunicabilidade (MAC), combinado com entrevistas sobre questões relativas à privacidade. Conclui-se que os usuários afirmam que se preocupam com a privacidade no Facebook no que diz respeito à divulgação de suas informações pessoais, em especial fotos, mas foram detectadas importantes rupturas de comunicação no que concerne a aspectos relacionados à privacidade de fotos.

\section{Introdução}

A Web 2.0, composta por sistemas de informação que permitem a interação social, além do compartilhamento de informações e da formação de grupos, permitiu que as redes sociais online se estabelecessem na vida das pessoas (Santana et al., 2009). A razão para a popularização desse tipo de sistema é que eles permitem uma maior interação entre seus usuários, mudando seu modo de relacionar e compartilhar informações sobre eles mesmos podendo até mesmo ajudar as pessoas a lidarem com problemas diários, como, por exemplo, situações que envolvem o trânsito (Lima et al., 2012). Por outro lado, o aumento da popularidade das redes sociais tem despertado inquietações diversas entre seus usuários, sendo uma das grandes preocupações a privacidade (Gill et al., 2011). Informações sobre os usuários disponibilizadas na rede podem atingir um alcance inimaginável, repercutindo de forma inesperada ou indesejada para o seu proprietário e suscitando, assim, questões relativas à privacidade. Como um exemplo disso, temos o trabalho de Pontes et al. (2012), que indicou que é facilmente possível inferir a 
localização da residência do usuário em redes sociais online a partir de suas informações publicamente disponibilizadas na rede.

Para usar as redes sociais online de forma adequada, evitando o surgimento de problemas relativos à violação de privacidade, faz-se necessário o usuário manter um controle sobre que informações suas estão disponíveis nesses sistemas e de que forma as mesmas podem ser apresentadas a terceiros, por meio de suas configurações de privacidade (Bergmann e Silveira, 2012). Tal fato exige um uso adequado do sistema, que ocorre através da interação do usuário com sua interface, que deve, por sua vez, indicar claramente a este as formas e mecanismos para gerenciamento do nível de privacidade de seus dados. Dessa forma, torna-se interessante avaliar como os sistemas de redes sociais online, através de suas interfaces, oferecem funcionalidades para controle efetivo de privacidade por parte dos usuários. Nesse contexto, o objetivo deste trabalho é avaliar como a privacidade é tratada dentro do Facebook, rede social de grande visibilidade atualmente e que possui recursos para o gerenciamento da privacidade dos dados de seus usuários. A contribuição do presente trabalho consiste em avaliar se a interface do Facebook permite que as interações que aí ocorrem favoreçam a melhoria da qualidade das relações humanas, voltadas especificamente para a privacidade, mostrando pontos que são vulneráveis no que tange a esse aspecto.

Na próxima seção, apresentamos a fundamentação teórica necessária para que se possa compreender melhor a metodologia, mostrada na seção 3 . Em seguida, na seção 4, apresentamos e discutimos os resultados obtidos e, finalmente, na seção 5, são apresentadas as conclusões e trabalhos futuros.

\section{Fundamentação Teórica}

\subsection{Engenharia Semiótica}

A Engenharia Semiótica (de Souza, 2005) entende a interface de um sistema interativo como sendo uma comunicação do projetista do sistema para os seus usuários. Esta mensagem (i.e. a interface) transmite aos usuários a quem o sistema se destina, que problemas ele é capaz de resolver e como interagir com ele para resolvê-los. À medida que o usuário interage com o sistema ele entende as questões sendo transmitidas pelo projetista. Assim, a interface de um sistema é tida como um artefato de metacomunicação, uma vez que a comunicação projetista-usuário se dá através da interação usuário-sistema. A comunicação proporcionada através dessa mensagem é realizada por meio dos signos dispostos na interface do sistema, sendo signo tudo aquilo que significa algo para alguém (Peirce, 1992 e 1998). A Engenharia Semiótica classifica os signos de uma interface em estáticos, dinâmicos e metalinguísticos (de Souza et al., 2006; de Souza et al., 2010). Signos estáticos são aqueles que expressam o estado do sistema, e podem ser percebidos ao se olhar para uma tela do sistema (ex. o texto de um botão). Já os signos dinâmicos expressam o comportamento do sistema e surgem da interação do usuário com ele (ex. ação disparada ao se selecionar em um botão). Por fim, signos metalinguísticos explicam outros signos da interface de forma direta (ex. sistema de ajuda).

Para avaliar a qualidade dessa comunicação entre projetista e usuário, a Engenharia Semiótica define a propriedade de comunicabilidade, que consiste na capacidade de um sistema transmitir de forma eficiente e efetiva aos usuários as 
intenções comunicativas do primeiro e princípios de interação, que guiaram o seu projeto (Prates et al. 2000; de Souza, 2005). Quando o usuário não é capaz de entender a comunicação pretendida pelo projetista, pode-se dizer que ocorrem rupturas de comunicação que podem dificultar ou até mesmo impossibilitar a metacomunicação ou o uso do sistema.

A Engenharia Semiótica provê métodos para avaliar a comunicabilidade de um sistema interativo, sendo que dois deles são utilizados neste trabalho e sucintamente explicados a seguir, para melhor entendimento da metodologia, apresentada na seção 3 .

\subsection{Método de Inspeção Semiótica - MIS}

O Método de Inspeção Semiótica (MIS) (de Souza et al., 2006; de Souza et al., 2010) é um método de inspeção em que o avaliador, especialista na aplicação do método, examina a interface de um sistema interativo, com o objetivo de identificar se existem rupturas de comunicação e então reconstrói a metamensagem enviada pelo projetista ao usuário através da mesma. O MIS é um método interpretativo e, como o usuário não participa da avaliação, é fundamental que o avaliador conheça a visão que o mesmo possui do sistema, para que possa falar em nome dele (de Souza et al., 2010). A aplicação do MIS é feita com base em um cenário que descreve o perfil do usuário, as partes do sistema sendo avaliadas e o contexto de uso sendo considerado.

A aplicação do MIS ocorre em cinco passos: (1) inspeção dos signos metalinguísticos; (2) inspeção dos signos estáticos; (3) inspeção dos signos dinâmicos; (4) consolidação e contraste e (5) apreciação da qualidade da metacomunicação. Nos 3 primeiros passos o avaliador inspeciona os signos em questão e reconstrói a metamensagem transmitida pelo projetista ao usuário através apenas da classe de signos em questão. No passo 4, o avaliador contrasta e compara as metamensagens reconstruídas nos passos 1 a 3 , procurando intencionalmente por significados contraditórios, inconsistentes ou ambíguos para os signos que as compõem, ou mesmo identificar situações em que a metamensagem ficou incompleta devido à ausência de signos que esclarecessem a intenção do projetista. No último passo, o avaliador apresenta a metamensagem completa do sistema, relatando sua apreciação final resultante da inspeção, através da apresentação e explicação dos problemas encontrados que possam dificultar ou impedir o usuário de entender a mensagem do projetista e, consequentemente, de interagir de forma eficiente e eficaz com o sistema.

\subsection{Método de Avaliação da Comunicabilidade - MAC}

O Método de Avaliação de Comunicabilidade - MAC (de Souza, 2005; Prates et al., 2000) é um método de caráter qualitativo, que envolve a observação de usuários, em ambiente controlado, por especialistas, que analisam a interação do usuário com o sistema e identificam as rupturas de comunicação por ele vivenciadas.

Após a execução dos testes com usuários, passa-se então para a etapa de análise dos dados, que é dividida em três passos: (1) Etiquetagem: gravações da interação são vistas pelos avaliadores e expressões (selecionadas a partir de um conjunto pré-definido de treze expressões) são associadas aos momentos de ruptura de comunicação, simulando a comunicação do usuário para o designer sobre a interface (Prates e Barbosa, 2007); (2) Interpretação: com base na etiquetagem, identificam-se classes de problema de comunicação projetista-usuário ou interação considerando a classificação das 
expressões que caracterizam a ruptura quanto ao tipo de falha (completas - expressões "desisto" e "para mim está bom", parciais - expressões "não, obrigado", "vai de outro jeito" ou temporárias - expressões "cadê", "ué, o que houve", "e agora?", "onde estou?", “epa!", "assim não dá”, "o que é isso?", "socorro", "por que não funciona?”) que representam na comunicação entre o sistema e usuário, a frequência e o contexto em que ocorrem as rupturas, a identificação de padrões de sequências de expressões e o nível da ação em que ocorre a ruptura (operacional, tático ou estratégico); (3) Geração do perfil semiótico: realiza-se a reconstrução da meta-mensagem sendo transmitida pelo projetista ao usuário através da interface, e à medida que o avaliador vai fazendo tal reconstrução, ele deve endereçar os desencontros entre o que o projetista pretendia dizer e as evidências de como os usuários estão interpretando o que ele diz.

\section{Metodologia}

Com o objetivo de compreender melhor o entendimento dos usuários sobre a privacidade no Facebook, foi disponibilizado um questionário online, no período de 23 de abril a 02 de maio de 2012. A divulgação foi feita por e-mail, e também no próprio Facebook, através da rede de contatos dos pesquisadores. O questionário foi respondido completamente por 175 pessoas com idade igual ou superior a 18 anos. Foram elaboradas 27 questões objetivas, divididas em três categorias: 1) Identificação do perfil do respondente e sua experiência no uso de redes sociais; 2) Caracterização do uso do Facebook; e 3) A privacidade no Facebook. As questões das categorias 2 e 3, específicas sobre o Facebook, somente foram respondidas por 170 participantes da pesquisa, que responderam afirmativamente que na época da pesquisa eram usuários ativos do Facebook. Os questionários foram tratados e analisados com vistas a identificar os recursos que os usuários mais utilizavam para preservar a sua privacidade.

A partir dos resultados obtidos com a análise dos questionários foi definido o escopo de avaliação do Facebook utilizando o MIS, bem como o cenário a ser utilizado. A inspeção aplicando o MIS foi feita por três avaliadores, alunos de doutorado, individualmente. Em um passo seguinte foi feita a consolidação dos resultados obtidos individualmente.

Para saber como os usuários efetivamente interagiam com os recursos do Facebook avaliados com o MIS, lançou-se mão do Método de Avaliação de Comunicabilidade (MAC). Os usuários foram recebidos pelos avaliadores, submetidos a uma entrevista pré-teste que permitia coletar dados sobre o seu perfil, colocados a interagir com o sistema realizando tarefas pré-determinadas e em seguida foram submetidos a uma entrevista pós-teste sobre as tarefas realizadas. O Método de Explicitação do Discurso Subjacente (MEDS) (Nicolaci-da-Costa et al., 2004) foi utilizado para a elaboração dos roteiros das entrevistas pré e pós-teste, bem como para a análise dos dados coletados por meio das mesmas.

\section{Resultados e Discussão}

\subsection{Recursos do Facebook utilizados e a privacidade}

Conforme apresentado na metodologia, 175 usuários do Facebook responderam o questionário que visava levantar o perfil de utilização do Facebook e mecanismos de proteção da privacidade. Com relação ao perfil dos respondentes, a maior parte deles 
(73\%) respondeu estar na faixa etária entre 18 e 27 anos, sendo que 59\% eram do sexo masculino e $41 \%$ do sexo feminino. Sobre o último nível de formação concluído, $45 \%$ disseram ensino médio, $38 \%$ graduação, $13 \%$ mestrado e $5 \%$ doutorado. A maior parte dos respondentes se enquadrou na área de Tecnologia da Informação (57\%), enquanto que $19 \%$ se enquadraram na área de Ciências Sociais Aplicadas, $10 \%$ na área de Ciências Humanas e 10\% em outras áreas de Ciências Exatas e da Terra. Em relação à experiência dos respondentes no uso de redes sociais, 99,4\% deles disseram que usavam ou já tinham utilizado o Facebook.

Nas questões sobre a caracterização do uso do Facebook, identificou-se que, dentre os principais motivos de uso, estão acompanhar atualizações de contatos $(71,2 \%)$, estabelecer e manter contatos $(58,8 \%)$ e compartilhar informações $(54,1 \%)$. Pôde-se perceber que as funções educativas e profissionais são de ordem secundária para o usuário. Sobre a frequência de utilização, percebeu-se que a maioria dos usuários do Facebook participantes da pesquisa utiliza com muita frequência o aplicativo (70\% usam mais de uma vez por dia), em especial em seções curtas (55\% de seções duram até uma hora e outras $19 \%$ duram de uma até 2 horas). Os recursos mais utilizados pelos respondentes da pesquisa são as mensagens e o bate-papo $(61 \%$ e $59 \%$ dos respondentes, respectivamente, os utilizam com frequência), apontando a preferência dos usuários por um uso mais privativo do sistema. Sobre o número e a qualidade das conexões dos usuários participantes da pesquisa, observou-se que a maior parte deles possui até 500 contatos no Facebook (78,2\% dos respondentes) e que a maior parte também não conhece todos os contatos que possui (64\% dos respondentes afirmaram conhecer a maioria dos contatos e apenas $32 \%$ disseram conhecer todos os seus contatos). A faixa de contatos de 251-500 e 501-1000 apresenta maior proporção de pessoas desconhecidas, indicando uma possível despreocupação do usuário com questões relacionadas à privacidade.

$\mathrm{Na}$ seção específica sobre privacidade, foi perguntado aos participantes da pesquisa se eles já tinham encerrado alguma conta em qualquer rede social, sendo que $48,6 \%$ deles responderam afirmativamente à pergunta, dos quais 83 respondentes apontaram os motivos, por meio de questão aberta para encerramento da conta. Foi realizada análise de conteúdo dos motivos de encerramento de conta em redes sociais, através da qual foram criadas categorias de resposta abrangendo falta de uso da rede; migração para outras redes; problemas de interação com a ferramenta ou usuários dela e problemas específicos e explicitamente ligados à privacidade. Por meio de questão aberta, foi possível identificar que problemas com privacidade (sentir-se exposto, ter falta de controle sobre o que é público, desconforto com o monitoramento, problemas em relacionamentos pessoais e até uma conta invadida foram o motivo de encerramento de contas em redes sociais por $9,7 \%$ dos respondentes da pesquisa ou $20,5 \%$ do total de 83 respondentes que apontaram motivos de encerramento de contas em redes sociais). Outro motivo para encerramento de contas em redes sociais, indicado por 16,9\% dos respondentes da pesquisa, foi categorizado como "Problemas na interface e/ou proposta de interação da ferramenta" e também está implicitamente ligado a problemas de privacidade, caracterizado pela queixa da baixa qualidade da interação pelos usuários e o excesso de informações/spams que os incomodam. Ainda na categoria relacionada à privacidade no Facebook, quando os usuários foram questionados sobre se já haviam tido problemas de privacidade usando tal sistema, apenas 14\% dos respondentes (24 
usuários) responderam afirmativamente, sendo estes usuários mais frequentes e/ou com maior número de contatos. Dos vinte e quatro usuários que relataram problemas de privacidade no uso do Facebook, 66,67\% deles tiveram acesso indevido de terceiros a suas informações restritas, $12,5 \%$ tiveram suas contas invadidas, $8,33 \%$ receberam informações indesejadas ou indevidas, enquanto $12,5 \%$ apontaram outros problemas de privacidade (e.g. o uso da conta por terceiros, ao esquecer o computador ligado conectado ao Facebook). Ainda dentre esses usuários, apenas dois deles deixaram de usar o sistema por este motivo e dezessete deles alteraram o modo de uso do Facebook após o problema, sendo que $52,94 \%$ destes restringiram o acesso de terceiros a informações privadas e $23,53 \%$ restringiram informações postadas no perfil. Além disso, vinte destes usuários disseram ter excluído amigos por motivos de violação de privacidade.

Partindo para outro ponto de investigação, foi perguntado aos respondentes do questionário que tipo de informação pessoal eles não divulgam no Facebook. Os dados relatados por meio de pergunta aberta revelaram que as pessoas aparentemente preocupam-se muito com informações pessoais (como dados da família, fotos e informações como endereço e localização, bem como viagens). Do total dos respondentes, $61,71 \%$ disseram que já limitaram o acesso aos seus dados - 108 de 175 dos quais 102 descreveram os tipos de restrições, em pergunta aberta. Foram obtidas 166 respostas válidas diferentes, que foram categorizadas, conforme mostrado na Tabela 1. Vale salientar que a coluna Casos/respondentes apresenta um total maior que $100 \%$ pois, no ato da categorização, a mesma resposta pôde ser incluída em uma ou mais categorias, já que era um campo de texto livre. É interessante notar que a limitação de acesso a fotos e a restrição de visualização de informações para grupos de amigos são os mecanismos mais utilizados para tratar questões de privacidade pelos usuários.

Tabela 1 - Dados limitados pelos usuários no Facebook

\begin{tabular}{|l|c|c|c|}
\hline \multicolumn{1}{|c|}{ Limitação de acesso a dados } & \multicolumn{2}{|c|}{ Respostas } & Casos/respondentes \\
\hline Limitar para pessoas específicas & N & \% resposta & \% casos \\
\hline Limitar fotos & 33 & $19,9 \%$ & $32,4 \%$ \\
\hline Limitar dados pessoais & 65 & $39,2 \%$ & $63,7 \%$ \\
\hline Limitar aplicativos & 29 & $17,5 \%$ & $28,4 \%$ \\
\hline Limitar informações de mural/postagens/feeds & 5 & $3,0 \%$ & $4,9 \%$ \\
\hline Todas as informações possíveis & 25 & $15,1 \%$ & $24,5 \%$ \\
\hline Outras & 4 & $2,4 \%$ & $3,9 \%$ \\
\hline Total & 5 & $3,0 \%$ & $4,9 \%$ \\
\hline
\end{tabular}

\subsection{Inspeção Semiótica das Interfaces - Aplicação do MIS}

A análise das respostas obtidas pelo questionário descrito na seção anterior mostra o compartilhamento de fotos como um recurso bastante utilizado (30\% dos respondentes o utilizam com bastante frequência), sendo que seu acesso é o mais restringido pelos usuários $(39,2 \%)$ em comparação a outros tipos de informação/recursos, devido a preocupações com privacidade. Assim, decidiu-se por focar o escopo das avaliações realizadas neste trabalho às funcionalidades do Facebook relacionadas às fotos, incluindo postagem, marcação e compartilhamento de fotos.

Para a inspeção com o MIS, conforme previsto pelo método, o primeiro passo foi gerar um cenário descrevendo o escopo da avaliação com foco nas interações 
relativas às fotos. A inspeção foi feita após o login no sistema, uma vez que apenas após esta ação é possível realizar as ações pertinentes ao escopo definido.

Após a geração do cenário, a inspeção foi conduzida individualmente por três avaliadores e, ao término das inspeções individuais, foi feita uma consolidação das análises, onde as potenciais rupturas identificadas por cada avaliador foram discutidas.

A partir da aplicação do Método de Inspeção Semiótica, pôde-se constatar que o Facebook proporciona diversas possibilidades de interações entre pessoas. No entanto, no que diz respeito à privacidade, dentro do escopo do presente trabalho, que se limita às suas funcionalidades relacionadas à postagem, compartilhamento e marcação de fotos, podemos dizer que o sistema apresenta rupturas de comunicação importantes, que podem levar o usuário a fazer um uso inadequado do mesmo. Apesar de o sistema apresentar uma aparente preocupação com a privacidade, manifestada pelos seus signos metalinguísticos (representados pelo seu sistema de ajuda e pelas páginas de "Política de uso de dados", de "Declaração de direitos e responsabilidades" e de "Princípios do Facebook"), na interface do sistema essa preocupação não é evidente, tendo em vista que é dado pouco destaque às opções de privacidade que o usuário pode manipular na interface, além da omissão de algumas informações que poderiam ser de grande valia para apoiar o usuário na decisão sobre o que deve ou não compartilhar. Um exemplo disso ocorre quando um usuário é marcado em uma foto. Mesmo sendo uma foto restrita apenas ao dono da foto, caso ele marque uma pessoa, esta ficará sabendo da marcação e todos os amigos da pessoa marcada poderão também ter acesso a esta foto. Apesar disso, o alerta sobre este fato na interface do sistema é ínfimo, se comparado às complicações sociais que podem ser geradas. Dessa forma, o usuário precisa ter um conhecimento prévio das ferramentas de privacidade para que possa conseguir restringir o acesso às pessoas que ele realmente deseja. Outro problema observado foi que, apesar de parecer que o compartilhamento de fotos em grupo protege mais o usuário, não há como ele filtrar/permitir que fotos ou comentários em seu nome sejam autorizados a serem colocados lá no grupo à semelhança da filtragem que acontece com a publicação no mural/linha de tempo do usuário e, apesar de não existir botão de compartilhamento de fotos postadas em grupos, o usuário pode fazer download delas.

Acredita-se que, pelas análises realizadas, o usuário deve ter maior cuidado em decidir o que deve ou não ser postado no Facebook, pois a mera seleção do público que visualiza a foto (como fotos postadas em grupo, por exemplo) ou a ausência de links de compartilhamento não evita que as fotos sejam baixadas e se espalhem pela rede sem que o usuário tenha conhecimento disso.

\subsection{Avaliando Recursos com Usuários - Aplicação do MAC}

Inicialmente, foi aplicado o teste com usuários, cujo propósito foi investigar a percepção do usuário sobre a privacidade do Facebook, para coleta de dados a serem analisados com o MAC. O teste foi conduzido em ambiente controlado, e todos os usuários assinaram um termo de consentimento de participação na pesquisa. Foram criados perfis de usuário específicos para o teste para que os participantes não tivessem que expor sua conta pessoal no Facebook. Para explorar as configurações de privacidade, foi solicitado a cada usuário individualmente que executasse cinco tarefas descritas no Quadro 1, inspiradas no mesmo cenário utilizado para a inspeção realizada 
na aplicação do MIS, com vistas a manter consistência na análise e possibilidade de cruzamento de resultados da pesquisa de uma etapa à outra.

\section{Quadro 1 - Tarefas realizadas pelo usuário no MAC}

\begin{tabular}{|c|l|}
\hline $\boldsymbol{N}^{\boldsymbol{}}$ & \multicolumn{1}{c|}{ Descrição da tarefa } \\
\hline $\boldsymbol{1}$ & $\begin{array}{l}\text { Postar uma foto em um álbum novo, criado especificamente para armazená-la, e compartilhar o } \\
\text { álbum com os amigos. }\end{array}$ \\
\hline $\mathbf{2}$ & Marcar um amigo em uma foto. \\
\hline $\mathbf{3}$ & $\begin{array}{l}\text { Alterar a configuração de privacidade de um álbum para compartilhá-lo apenas com os amigos } \\
\text { de uma lista específica. }\end{array}$ \\
\hline $\mathbf{4}$ & Remover a marcação do próprio usuário em uma foto postada por um amigo. \\
\hline $\mathbf{5}$ & $\begin{array}{l}\text { Alterar as configurações de privacidade de forma que o usuário possa decidir, antes da } \\
\text { marcação ser publicada na rede, se ele quer ou não que a mesma seja publicada. }\end{array}$ \\
\hline
\end{tabular}

Para o teste, optou-se por selecionar participantes que possuíam familiaridade com recursos da tecnologia, mas que não possuíam experiência nas configurações de privacidade alvo do teste (configurações de privacidade sobre fotos e recursos de marcação). Os participantes foram selecionados pela sua disponibilidade a partir da rede de contato dos avaliadores. É interessante registrar que nem todos os avaliadores conheciam todos os participantes, e atribuiu-se o papel do observador na sala de teste a um avaliador que não era conhecido do participante.

Dos cinco participantes selecionados, dois eram graduandos, um mestrando e dois mestres, com idade entre 18 e 38 anos. O perfil dos selecionados é compatível com os respondentes do questionário da etapa 1 deste trabalho, sendo três deles da área de tecnologia da informação. Vale salientar que, embora esta seleção possa parecer inadequada para realização do MAC, pôde-se notar que o fator conhecimento da tecnologia da informação não influenciou na avaliação dos recursos de privacidade, conforme foi evidenciado nas entrevistas que adiante serão analisadas. Todos os participantes faziam uso do aplicativo por, no mínimo, um ano e meio, embora a frequência de utilização fosse variável: um usuário esporádico e outros mais frequentes. O modo de interação é compatível com o levantado no questionário da primeira etapa desta pesquisa: uso diário e com interações curtas a cada entrada (logada) no sistema. Outro aspecto convergente do perfil dos participantes foi o fato de nem todos eles conhecerem pessoalmente todos os seus contatos, embora nem todos estejam na faixa de 250-500 contatos predominante na aplicação do questionário. Neste trabalho, serão utilizadas as siglas P1, P2, P3, P4 e P5 para identificar cada um dos cinco participantes do teste, respeitando assim o anonimato destes.

No que diz respeito aos fatores que podem interferir na realização do teste, notase que três dos usuários não utilizavam o recurso de marcação de fotos, enquanto um deles sequer postava foto no aplicativo, o que torna o método MAC interessante de ser aplicado, já que seria desejável menos experiência nas funções em análise para o método ser aplicado. Embora o usuário P5 tenha demonstrado, na entrevista pré-teste, ser mais proficiente que os demais, ele revelou não conhecer todos os recursos de privacidade, sendo a coleta e análise de seus dados pertinente para os propósitos desta pesquisa.

A interação gravada durante os testes foi analisada pelos três avaliadores com o auxílio do software Morae ${ }^{\circledR}$, módulo Analyzer ${ }^{\circledR}$. Para a etiquetagem, os avaliadores assistiram aos vídeos com a gravação da interação de cada participante, identificando 
pontos onde ocorrem rupturas e atribuindo a estes uma ou mais etiquetas do MAC, remetendo a um tipo de problema de comunicação designer-usuário na interface (Prates e Barbosa, 2007; Barbosa e Silva, 2010).

A tarefa 1 foi realizada com facilidade pela maior parte dos usuários, sendo a maior parte das rupturas ocorridas provenientes de um único usuário, que revelou nunca ter realizado as tarefas exigidas no teste. No que diz respeito ao resultado do compartilhamento/postagem para os amigos, foi perguntado aos participantes, na entrevista pós-teste, quem eles achavam que teriam acesso à foto compartilhada. Três deles responderam que seriam todos os seus amigos, porém dois participantes demonstraram ter dúvidas se seriam apenas seus amigos. A incerteza dos usuários quanto ao resultado da ação é expressa na fala de alguns participantes, como por exemplo "A princípio, todos os meus amigos", sendo o uso do "A princípio" um marcador de incerteza no discurso. Outro participante explicita o motivo da sua dúvida: “(...) uma vez que os amigos vão ver... eu fiquei com dúvida se um amigo quiser compartilhar se aí vai começar a passar para frente". Neste caso, apesar do participante em questão ter executado a tarefa com facilidade, ele demonstrou não ter clareza sobre as possibilidades de visualização da foto postada.

Em relação à tarefa 2 , todos os participantes conseguiram concluí-la com facilidade, porém, na entrevista pós-teste, ao serem perguntados sobre quem teria acesso à marcação, quatro dos cinco responderam erroneamente que seriam os seus amigos e os amigos da pessoa marcada e um deles pensou na configuração de privacidade para responder, acreditando corretamente que, além dos seus amigos e dos amigos da pessoa marcada, os amigos dos seus amigos também veriam a marcação e que seria necessário saber a configuração de privacidade do amigo para responder.

A tarefa 3 foi concluída por todos os participantes com facilidade, tendo ocorrido poucas rupturas. Isso provavelmente se deu pelo fato de haver mais de uma possibilidade para configurar a privacidade de um álbum. No entanto, ao serem questionados a respeito de quem teria acesso às fotos do álbum compartilhado com a lista, mais uma vez os participantes demonstraram falta de segurança ou certeza quanto à restrição de postagem no Facebook. Espontaneamente, todos os participantes disseram que quem teria acesso às fotos do álbum seriam apenas os participantes da lista, mas, ao serem questionados se a marcação feita anteriormente em uma foto do álbum em questão perderia o efeito, eles foram vagos na resposta, três deles dizendo que talvez os amigos da pessoa marcada anteriormente continuassem com acesso e outros dois, que talvez não.

Na tarefa 4 observou-se um grande número de rupturas. Isto ocorreu pelo fato de não existir a opção de remover marcação explicitamente na página da foto a ser desmarcada. Dessa forma, dois usuários selecionaram o link "Remover", pensando que estariam removendo a marcação da foto, mas na verdade estavam removendo a foto do seu perfil. Desses dois usuários, um percebeu que havia realizado a ação incorretamente e então conseguiu depois remover a marcação; porém o outro usuário não percebeu o erro e deu a tarefa como encerrada. No entanto, para o usuário remover a marcação da foto, faz-se necessário que ele posicione o ponteiro do mouse no interior da área preta sobre a qual é exibida a foto, para que apareça o menu "Opções", que exibe o item "Denunciar/remover marcação", quando o usuário seleciona o mesmo. Na entrevista 
pós-teste, quando os participantes foram questionados sobre o resultado da ação de remoção de marcação, estes se mostraram inseguros sobre seus efeitos, isto é, se a marcação continuaria acessível aos amigos da pessoa que a marcou ou não. Assim, embora a questão pareça simples, quando discutida em detalhes revela sua complexidade, diante da natureza do sistema caracterizado como rede social.

A tarefa 5 revelou dúvidas dos participantes em relação ao comportamento do sistema. Houve um número considerável de rupturas, uma vez que, mesmo encontrando as opções de configuração, os participantes tiveram dificuldades em selecionar quais delas eram relevantes para a tarefa. Para ativar essa opção, é necessário que o usuário vá até a página de Configurações de privacidade, através de um ícone situado na extremidade direita da barra azul localizada na parte superior do Facebook. Somente um participante selecionou a opção errada de "configuração de conta" no lugar de "configuração de privacidade", porém, demonstrando que provavelmente não é um problema encontrar a opção de configuração adequada. Outro aspecto marcante foi que todos selecionaram, dentro da opção de configuração, o item correto de "Perfil e Marcação - Editar Configurações", parecendo que a mensagem do designer é clara neste aspecto (quanto à identificação das opções de configuração de marcação). Na página de "Configurações de privacidade", é necessário que o usuário altere as suas configurações de "Perfil e marcação", acessando o link "Editar configurações". Quatro entre os cinco participantes ativaram, além da opção necessária para executar a tarefa, outra opção que também diz respeito a marcações, mas, no caso, para analisar marcações de seus amigos em suas próprias publicações no Facebook. Tal fato gerou rupturas, tendo em vista que os usuários não perceberam que estavam ativando uma opção não solicitada pela tarefa.

Particularmente neste caso, pelo fato de ter originado rupturas completas, é interessante notar as dúvidas verbalizadas durante as entrevistas a respeito desta tarefa. Apesar de todos terem acessado o item correto da configuração, todos, sem exceção, não tiveram certeza sobre as ações que realizaram. Mesmo o único participante que executou a tarefa com sucesso relatou: “(...) eu nem sei se eu fui no lugar certo, não tenho certeza, não sei se era exatamente ali (...) o texto falou (...) que eu poderia continuar marcada e continuar aparecendo em outros lugares no Facebook, então, eu não entendi nada". É importante notar ainda, no caso da configuração dos recursos de privacidade, que todos os usuários consideraram a redação do texto confusa e pouco clara, aspecto que também foi percebido pelos avaliadores na aplicação do MIS.

Foram analisadas as entrevistas pré e pós-teste nas questões relativas à privacidade por meio do MEDS, conforme já mencionado. Nas respostas inter-sujeitos, a ocorrência que parece mais significativa, aos olhos dos pesquisadores, é a incerteza. São várias as falas explícitas sobre a falta de clareza da ferramenta e se é possível o controle da privacidade com os recursos da ferramenta. Os participantes falam explicitamente que é preciso testar (P1, P4 e P5) ou vivenciar situações para saber os efeitos do compartilhamento.

No que diz respeito à análise intra-sujeitos, nota-se, na fala de $\mathrm{P} 1$, preocupação com o ocultamento das informações pessoais, ao relatar ter abandonado a postagem de fotos, tendo em vista já ter tido problemas de relacionamento afetivo por causa da ferramenta. Já a fala de P5 revela uso diferenciado da ferramenta: para estar mais próximo de poucos amigos (preferência por uso de mensagens pessoais, acompanhar 
atualizações dos melhores amigos). Talvez por esta razão tal usuário não tenha entendido bem o significado do que seria "informação pessoal", tendo perguntado aos pesquisadores o que seria isso.

$\mathrm{O}$ participante $\mathrm{P} 3$, por sua vez, revelou pouca preocupação com a privacidade em relação aos demais usuários (posta informações de localização, por exemplo, coisa que o participante P1 acha pouco recomendável), e paradoxalmente, foi o que mais parecia estar atento às configurações de perfil de privacidade ao responder sobre o acesso às fotos marcadas.

O participante $\mathrm{P} 4$ revelou um perfil aparentemente pragmático: fechamento das informações de perfil e publicação (semelhante à escolha de P5). O participante P2, por utilizar ocasionalmente, não se preocupa com as questões de privacidade.

Parece que quanto maior a exposição, mais as pessoas se calam, falando daquilo que não as comprometem, postando o mais básico do seu perfil. A confusão entre a intimidade a privacidade podem ser problemáticas, conforme afirma a fala do participante P2: "Porque eu praticamente não coloco nada pessoal, então, não sou muito preocupado com isso". É interessante notar que a autocensura é também evidenciada nos questionários da etapa 1 deste trabalho, onde as pessoas responderam que procuram restringir postagens pessoais (como localização) ou fotos em seus perfis.

\section{Considerações finais}

A realização do questionário permitiu notar que os usuários do Facebook não têm muita consciência de uso dos recursos de privacidade do aplicativo, embora se preocupem com a divulgação de suas informações pessoais. Com a aplicação do MIS pôde-se constatar que o sistema apresenta rupturas de comunicação graves em sua interface, no que concerne a aspectos relacionados à privacidade de fotos. Concluímos que o Facebook não é claro quanto aos destinatários das postagens de fotos e marcações realizadas pelos seus usuários. Tal fato justifica o desconhecimento por parte do usuário dos recursos do sistema que permitem a manipulação de funcionalidades ligadas à privacidade, fato esse detectado precocemente, na análise das respostas do questionário.

Por fim, com a aplicação do MAC, em conjunto com as entrevistas que foram realizadas antes e após os testes realizados com os usuários, pôde-se confirmar que estes realmente apresentam problemas para compreender aspectos presentes na interface do sistema que remetem a ações relacionadas à privacidade. Além disso, muitas vezes o usuário não possui conhecimento sobre qual será a repercussão dessas ações dentro do sistema, levando-o possivelmente a agir de forma inconsistente com seus desejos e intenções. Os testes com usuários realizados no Facebook apontam grande incerteza destes acerca dos efeitos de suas ações em relação aos mecanismos de privacidade relacionados aos recursos de publicação de fotos. Tal fato indica a não ocorrência de um controle de privacidade efetivo pelos usuários, em seu contexto real de uso.

Um próximo passo interessante seria elaborar uma ferramenta que permitisse ao projetista de sistemas colaborativos identificar potenciais problemas sociais, como a privacidade, ainda em fase de projeto da aplicação, para que estes sejam evitados antes mesmo da liberação do sistema. 


\section{Agradecimentos}

Agradecemos o apoio da CAPES, FAPEMIG e do INCT-Web (INWeb) (MCT/CNPq n ${ }^{\circ}$ 57.3871/2008-6) a esta pesquisa. Somos gratos também aos voluntários que responderam ao questionário e participaram da avaliação.

\section{Referências}

Bergmann, F. B.; Silveira, M. S. (2012) "Eu vi o que você fez... e eu sei quem você é!": uma análise sobre privacidade no facebook do ponto de vista dos usuários. Anais do XI Simpósio Brasileiro de Fatores Humanos em Sistemas Computacionais (IHC 2012). SBC, 109-118.

de Lima, V. G.; Magalhães, F. de M. R.; Tito, A. de O.; dos Santos, R. A.; Ristar, A. R. R.; dos Santos, L. M.; Vieira, V.; Salgado, A. C. (2012) "UbibusRoute: Um Sistema de Identificação e Sugestão de Rotas de Ônibus Baseado em Informações de Redes Sociais”. VIII Simpósio Brasileiro de Sistemas de Informação, SBSI 2012.

de Souza, C. S, Leitão, C. F., Prates, R. O., Bim, S. A., da Silva, E. J., (2010). "Can inspection methods generate valid new knowledge in HCI? The case of semiotic inspection”. International Journal of Human-Computer Studies, v.68, p.22-40.

de Souza, C. S., Leitão, C. F., Prates, R. O., da Silva, E. J., (2006). "The Semiotic Inspection Method". Anais do VII IHC - Simpósio de Fatores Humanos em Sistemas Computacionais. Natal - RN, p. 148-157.

de Souza, C. S. (2005). "The semiotic engineering of human computer interaction". MIT Press, Cambridge MA.

Gill, A. J; Vasalou, A.; Papoutsi, C.; Joinson, A. (2011) "Privacy Dictionary: A Linguistic Taxonomy of Privacy for Content Analysis". CHI 2011, Session: Privacy May 7-12, 2011, Vancouver, BC, Canada.

Nicolaci-da-Costa, A.M.; Leitão, C.F.; Romão-Dias, D. (2004) "Como conhecer usuários através do Método de Explicitação do Discurso Subjacente (MEDS)". VI Simpósio Brasileiro sobre Fatores Humanos em Sistemas Computacionais, IHC 2004. Curitiba, outubro de 2004.

Peirce, C. S., 1992, 1998. The essential Peirce (Vols. I and II). Editado por Nathan Houser e Christian Kloesel. IN: Indiana University Press, Bloomington.

Pontes, T., Magno, G., Vasconcelos, M., Gupta, A., Almeida, J., Kumaraguru, P., and Almeida, V. (2012) "Beware of What You Share: Inferring Home Location in Social Networks". In: International Workshop on Privacy in Social Data (PINSODA), 2012, Bruxelas, Bélgica. Proc. International Workshop on Privacy in Social Data, 2012.

Prates, R. O. ; Barbosa, S. D. J. (2007) "Introdução à Teoria e Prática da Interação Humano-Computador fundamentada na Engenharia Semiótica”. In: T.Kowaltowski e K. K. Breitman (Org.). In JAI 2007.

Prates, R. O., de Souza, C. S., Barbosa, S. D. J., (2000). "A method for evaluating the communicability of user interfaces”. In Interactions, v. 7, n. 1, p. 31-38.

Santana, V. F; Melo-Solarte, D. S.; Neris, V. P. de A.; De Miranda, L. C.; Baranauskas, M. C. "Redes Sociais Online: Desafios e Possibilidades para o Contexto Brasileiro". Em: Anais do XXXVI Seminário Integrado de Hardware e Software, 2009. 